\title{
A geographic identification of multidimensional poverty in rural China under the framework of sustainable livelihoods analysis
}

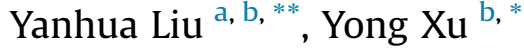 \\ a School of Economics, Zhejiang University of Finance and Economics, Hangzhou, Zhejiang, 310018, China \\ ${ }^{\mathrm{b}}$ Institute of Geographic Sciences and Natural Resources Research, Chinese Academy of Sciences, Beijing, 100101, China
}

\section{A R T I C L E I N F O}

\section{Article history:}

Received 4 October 2015

Received in revised form

16 June 2016

Accepted 19 June 2016

Available online 1 July 2016

\section{Keywords:}

Multidimensional poverty

Geographic identification

Vulnerability

Sustainable livelihood

Rural China

\begin{abstract}
A B S T R A C T
Developing methods of measuring multidimensional poverty and improving the accuracy of poverty identification have been hot topics in international poverty research for decades. They are also key issues for improving the quality and effectiveness of rural poverty reduction programs in China. So far, selection and integration of poverty indicators remains the main difficult for measurement of multidimensional poverty. Guided by the sustainable livelihoods framework developed in the UK by the Department for International Development (DFID), an index system and an integration method for geographical identification of multidimensional poverty were established, and they were further used to carry out a county-level identification of poverty in rural China. Additionally, comparisons were made of the identification results with counties having single-dimension income poverty in rural areas and poor counties designated by the Chinese central government. The results showed that a total of 655 counties, with 141 million rural residents, were identified as multidimensionally poor. They are concentrated and conjointly distributed geographically, and evil natural conditions are their common features. In comparison to the income poor and the designated poor counties, the multidimensionally poor counties were not only worse in single-dimensional and composite scores, but also having multiple disadvantages and deprivations. By identifying the disadvantage and deprived dimensions, the measurement of multidimensional poverty should be very helpful for each county to work out and implement antipoverty programs accordingly, and it would make contribution to improve the sustainability of poverty reduction. Hopefully, this research may also shed light on multidimensional poverty measurement for other developing countries.
\end{abstract}

() 2016 Elsevier Ltd. All rights reserved.

\section{Introduction}

Poverty has been an objective phenomenon throughout human history and the process of human social development. It is a worldwide problem that concerns all nations, especially developing countries. A series of mid- and long-term antipoverty and development plans and poverty reduction policies implemented by the central government has played a major role in a dramatic decrease of poverty in the Chinese population (Ravallion, 2009; Wang, Li, \& Wang, 2009; World Bank, 2009). However, the designation of particular regions in China as "poor" has been criticized by

\footnotetext{
* Corresponding author.

** Corresponding author. School of Economics, Zhejiang University of Finance and Economics, Hangzhou, Zhejiang, 310018, China.

E-mail addresses: yhliu2014@zufe.edu.cn (Y. Liu), xuy@igsnrr.ac.cn (Y. Xu).
}

academics and citizens alike who question the accuracy and reliability of the methodology (Park, Wang, \& Wu, 2002; Riskin, 1994; Wang et al., 2007). As population of the remaining poor in rural China is getting less and, at the same time, the efficiency of poverty reduction is declining, improving the accuracy of poverty targeting and implementing corresponding strategies are widely acknowledged to be imperative for the next phrase of poverty alleviation (Park \& Wang, 2010; Wang et al., 2007). Although estimates of per capita gross domestic product and financial revenue for local government are now included in the identification of poor regions, it remains clear that the indicators of poverty are primarily economic in China (Labar \& Bresson, 2011; Wang, Qian, \& Duan, 2013; Zuo \& Fang, 2011). Accordingly, most of the antipoverty policies and strategies were orientated towards improving these economic indicators, which lead to a less sustainable effectiveness of poverty reduction and high rate of poor people falling-back-into-poverty. In the 1980s, the concepts of capability poverty and entitlement 
poverty, first described by the Nobel Prize winner Amartya Sen (Sen, 1982, 1985), expanded the view of poverty beyond its traditional economic context. Since that time, it has become generally accepted worldwide that the concept of poverty should include not only economic shortages, but also social exclusions, lack of opportunity or public services, and vulnerability or exposure to risks of those deficits (UNDP, 2010a; Wagle, 2002; World Bank, 2000). Consequently, the measurement of poverty evolved from onedimensional measurement of income/consumption to multidimensional measurement of income, education, health, nutrition, resources, environment, location, and vulnerability. Actually, the remaining poor in rural China are experiencing severe multidimensional deprivations beyond economic shortage (Cao, Wang, \& Wang, 2009; Glauben et al., 2012; Xiong, 2001). Therefore, developing method for identification of multidimensional poverty becomes an urgent and meaningful trial for China to improve its accuracy of poverty targeting and promote the effectiveness of poverty reduction.

Current methods of measuring multidimensional poverty have been described in numerous publications (Alkire \& Foster, 2011; Cavatassi, Davis, \& Lipper, 2004; Cohen, 2009; Maasoumi \& Lugo, 2008; Ravallion, 2011; Tsui, 2002), but selection and integration of poverty indicators remain difficult (Bourguignon \& Chakravarty, 2003; Ferreira \& Lugo, 2012). In China, most studies of multidimensional poverty have lacked innovation, mainly concentrating on application of international developed methods to small geographic regions of the country (Chen, 2008; Liu et al., 2014; Wang \& Alkire, 2009). Indicators used to measure multidimensional poverty are chosen and used for three reasons. First, because they were used to describe the main characteristics or basic demands of poor people in previous investigations (Alkire \& Santos, 2010; Davis, 2003; Dorling et al., 2007; Henninger, 1998). Second, because they are consistent with investigator-defined concepts of poverty or the antipoverty targets to be addressed (Achia, Wangombe, \& Khadioli, 2010; Krishna et al., 2006; Wang, Cheng, \& Zhang, 2012). Third, because they are consistent with existing poverty theory or analytic frameworks (Cohen, 2009; Sharp, 2003). However, when conducting research, it is hard to systematically and accurately measure all the economic and social variables because of trade-offs between theoretical models and the accessibility of data (Davis, 2003). Consequently, the experimental approach based on the method described above is open to question.

Two main approaches are usually adopted for the integration of the indicators of multidimensional poverty (Alkire \& Foster, 2011; Deichmann, 1999). One is to develop a tool to aggregate individual dimensions into a composite poverty index that is used to indicate whether a person or region is poor. It is quite easy to score poverty in this way, but weighting the contribution of each indicator is a key difficulty. It can be argued that the outcome of this approach to measure multidimensional poverty may not be very different from that obtained by measuring single dimensional poverty (Ferreira \& Lugo, 2012). Actually, the true value of the notion of multidimensional poverty is that the contents of each dimension are not totally substitutable (Bourguignon \& Chakravarty, 2003). Another method of estimating multidimensional poverty, called the counting approach (Atkinson, 2003), identifies the number of deprived dimensions. In this approach, a deprivation cutoff is specified for each dimension and then individuals or regions that fall below the cutoff are identified. A decision on whether a person or region is poor is ultimately based on a predefined minimum number of dimensions of deprivation. This "dual cutoff" identification system gives clear priority to those with multiple deprivations, and is well suited for populations and places with many existing disadvantage dimensions (Alkire \& Foster, 2011). The method is limited, however, in that interactions among different dimensions are neglected. Guided by a wellknown and widely used conceptual framework of sustainable livelihoods proposed by the Department for International Development in the UK (DFID, 1999-2005), this research tried to develop a method for identification of multidimensional poverty in rural China by building an indicator system and improving the existing integration method through method inference, content comparison and indicators selection and tested.

Identification of poverty generally targets either people/households directly or geographic regions of different scales. Different target strategies are essential for the effectiveness of antipoverty programs (Krishna, 2007; Neto, 2001; Nhate \& Simler, 2003). Investigations of poverty in countries or regions with small or scattered populations of poor people tend to identify and target people and households, whereas countries or regions with large populations of poor people concentrated in particular areas, as in China, tend to target geographic units. The latest official data indicate there are still more than 100 million poor people living in rural China, and they are densely concentrated in western mountainous regions (Cao et al., 2009; Glauben et al., 2012; Yue, Li, \& Wang, 2005). The characteristics of Chinese rural poverty make it necessary for government to implement antipoverty projects based on data from geographic targeting. Therefore, this paper is going to carry out a geographic identification at county level, which is also the basic geographic unit for China's past designation of poor areas.

Generally speaking, the main aim of this research is to try to improve the effectiveness of poverty reduction programs in rural China by understanding persistent poverty from a multidimensional and dynamic perspective. Also, by proposing an improvement in the method for multidimensional poverty measurement, this research would like to make a contribution to poverty measurement internationally, especially for those developing countries which have significant persistent poverty and relatively concentrated spatial distribution of them but lack of data from individual or household level. Section 2 introduced the DFID framework, indicator system, methodology, data and resources. Section 3 was result analysis, including single dimensional, multidimensional results and comparison and appraisal of results. Section 4 is the conclusion and discussion.

\section{Methodology and data}

\subsection{Framework basis}

The Sustainable Livelihoods Approach, an integrative analysis framework developed within the past 20 years to understand the causes of poverty and to provide multiple solutions, considers both the factors leading to poverty and the complex problems associated with it (Chambers \& Conway, 1992; Ellis, 2000; Roberts \& Yang, 2003). Livelihoods analysis frameworks emphasizing different aspects of poverty have been proposed by various international groups and institutions (Cannon, Twigg, \& Rowell, 2003; Frankenberger, Drinkwater, \& Maxwell, 2000; Hulme, Moore, \& Shepherd, 2001; IFAD). The approach developed by the DFID is one of the most widely applied (Li et al., 2007, 2012; Sharp, 2003). This framework (Fig. 1) integrates five sets of data called the vulnerability context, livelihood assets, transforming structures and processes, livelihood strategies, and livelihood outcomes (DFID, 1999-2005). The vulnerability context means that the external environment in which people exist is generally vulnerable. It can be critical trends, shocks and seasonality over which people have limited or no control. The livelihood assets refer to the categories of assets that people require to achieve positive livelihood outcomes, including financial, human, social, physical and natural capital. The transforming structures and processes are the institutions, 


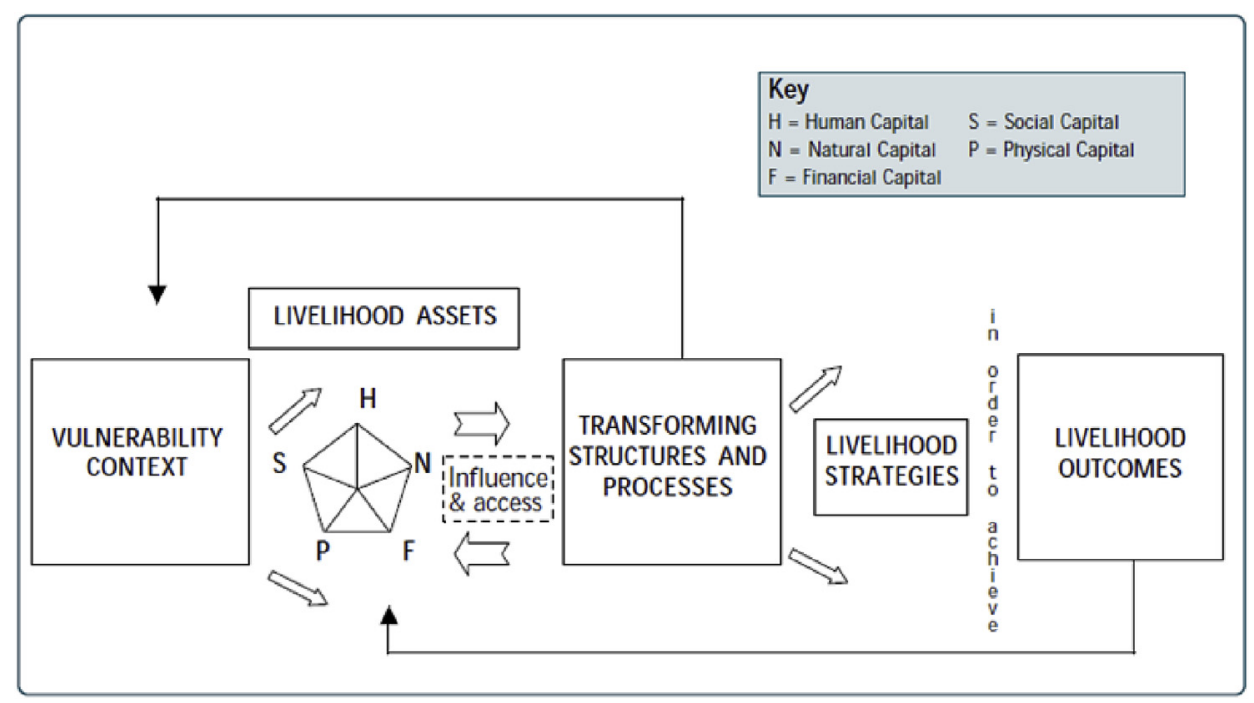

Fig. 1. The sustainable livelihoods framework developed by the DFID (1999-2005).

organizations, policies, legislation and culture that shape livelihoods. The livelihood strategies denote the range and combination of activities and choices that people make/undertake in order to achieve their livelihood goals, including productive activities, investment strategies, reproductive choices, etc. The livelihood outcomes are the achievements or outputs of livelihood strategies.

The DFID approach considers the state of a household's livelihood to be determined mainly by the quantities and qualities of the livelihood assets it possesses. The composite structure of these five variables formulates the "pentagon of livelihoods," which dramatically decreases in size if a household lacks, or has an imbalance of, certain assets. The context of vulnerability may have a direct or indirect impact on the pentagon of livelihoods, and transforming structures and processes will improve or worsen a household's state of livelihood by working directly on the vulnerability context or livelihood assets. To achieve expected livelihood outcomes, a household has to adopt proper livelihood strategies that take all the available capitals, the vulnerability context, and the transforming structures and processes into consideration. The livelihood outcomes not only affect a household's state of livelihood, but also determine the accessibility of additional assets for further livelihood improvements.

Household poverty is determined primarily by the state of its livelihood and its sustainability. The whole evolving process of livelihoods is dynamic and sustainable, and mainly presents in how the household uses all the assets it owns and adopts the right strategies to cope with the context of vulnerability, eliminate the negative aspects of transforming structures and processes, seize opportunities in them and achieve expected outcomes, so that the state of its livelihood can be improved. This process can be expressed by the formula:

$L_{t+1}=f\left(V_{t}, L_{t}, P s_{t}, S t_{t}, O_{t}\right)$

where $L_{t+1}$ is the future state of a household's livelihood, and $V_{t}, L_{t}$, $P s_{t}, S t_{t}$, and $O_{t}$ are the existing vulnerability context, state of livelihood, transforming structures and processes, livelihood strategies and livelihood outcomes.

The aim of poverty identification is to help policymakers design antipoverty policies and programs. To minimize the influence of existing structures and processes, their spatial disparity is not considered in this study. Households are assumed to be economically rational, thus the best livelihood strategies and outcomes can be determined by the existing vulnerability context and livelihood assets. That is to say, the future state of a household's sustainable livelihood would be determined by the current asset composition and vulnerability context. If households are economically rational, then Formula (1) can be simplified, with:

$L_{t+1}=g\left(V_{t}, L_{t}\right)$

\subsection{Indicator system for poverty identification}

Based on the analysis of DFID framework above, the indicator system for geographic identification of poverty in rural China comprises six dimensions, i.e., five assets and the vulnerability context. Considering that data for households is unavailable, this research adopted regional data. For the whole China, the smallest geographic unit for obtaining relatively complete and universal data is county, and it is also the choice of scale for China's past designation of poor areas, and for this research as well. To avoid the ecological fallacy caused by conflict of spatial scale between the household level analysis of DFID framework and the county level data, indicators selected in county level were confined to rural areas if possible and tried to be in accordance with household level and closely associated with livelihoods of rural households. Specifically, the indices used to identify multidimensional poverty in rural China were chosen as follows. First, the contents of the six DFID framework dimensions were broken down into measurable objectives, and their relative contributions to livelihood status were carefully analyzed. Then potential indices at household level corresponding to each influence that seemed prominent and measurable were preliminarily chose, and the county-level indices corresponding to them were found. To confirm the effectiveness and credibility of these indices applied for measurement, statistical, spatial, and correlation analyses were carried out. Finally, 13 feature indicators and 22 attribute indicators from the six dimensions were chosen as indices of multidimensional poverty in rural China. Considering that 2354 counties were involved and it is uneasy to check every indicator for each county, ecological fallacy may still exist though large number of indices can partly lessened the risk. The statements for indices choice in each dimension and their weights allocation are as follows. 
To guarantee the conciseness of indicator systems, this research only chose those very useful and representative indicators that had accessible data and been used in precedent research, but gave up those contents that had little influence on the result and lack of appropriate corresponding indices.

Income, saving and loan are three main sources for financial capital. Since data for savings and loans of rural residents are unavailable, net per capita income of rural residents was used for measuring income. Using income as indicator of economic poverty is a tradition. It is believed to be good enough for measuring the financial situation of rural households for engaging in livelihood activities.

For the dimension of human capital, capability of labor, level of education and competent for jobs are among the most important for livelihood. Composite capability of labor was weighted integrated by percentage of rural labors in different age and sex groups, in which the teenagers and females are thought to be less productive than grownups and males. The status of nutrition and health is neglected because lack of data. Composite level of education was weighted integrated by percentage of rural labors in different education level, in which literacy and college are deemed to be two significant divisions of education level for potential productivity. The composite competent for jobs, representing skills or job possibilities, was weighted calculated by percentage of rural people engaging in agricultural and non-agricultural jobs.

Natural capitals that rural people can get access to and benefit from mainly include agricultural lands and water. For the data reason, average area of farmland per rural person and average grain production per sown area were used to express the quantity and quality of farmland. The accessibility of water resources was roughly indicated by average precipitation for ten years, because tap water and irrigation system in many rural areas of China are still unavailable. Other natural resources, like hydro, mineral, biotic resources, do have a great contribution to local economy, but it is very rare that rural individuals can take part in the usage of these resources directly and gain the benefit. Therefore, they were not included in the measurement.

The physical capitals mainly comprise of public infrastructures, housing, livestock and tools for production, appliances and other durable goods. Since there are so many kinds of infrastructures, which makes their data hard to be collected and integrated, this research only took the percentage of transportation land as the indicator. Nevertheless, it is noteworthy that the data may cover up the real situation of transportation in rural areas because rural data is unavailable. The level of housing is measured by average number of rooms per rural person. The level of tools for production adopted the average power of agricultural machinery per rural person. The ownership of durable goods was evaluated by average electricity consumption per rural person.

Close relationship, social participation to groups or events and supports from social institutes or processes are the most important components of social capital. However, data for them are not available. Considering social capital mainly works for job opportunities and social supports for people's livelihoods, level of urbanization can partly express the chances that rural people keep contact with urban people or obtain jobs in urban area, and the income ratio between rural and urban residents and percentage of minorities in rural area can represent, to some extent, the level of social exclusion, the opposite of social support.

The vulnerability context expresses the extent of rural people's exposure to sudden natural or human disasters or evil trends. The most influential natural disasters on rural areas and their economies in China include meteorological disasters like rainstorm, drought and flooding, and geologic hazards like earthquake and landslide (Wang, Zhang, \& Liu, 1995). Except earthquake, the other disasters have close relationship with temperature, radiation, precipitation, elevation and slope. However, among them, only the negative impact of slope on all these natural disasters is definite, so this research took percentage of areas with gradients higher than $15^{\circ}$ as the indicator of natural disasters. For other risks and trends that is easy to measure, endemic is a good signal of evil trends for human capital, so percentage of people older than 80 in rural areas was applied to indicate the trend for health of local rural people in view of data for endemic is unobtainable.

The complexity of this indicator system makes the frequently used objective methods of weighting, which assign weights according to the distribution of data itself, have obvious defects. Comparatively, designating weights on the basis of the contribution that each indicator makes to livelihood outcome makes more sense. The rank correlation analysis method of weighting proposed by Chen, Guo, and Yu (2011) was an improved method from analytic hierarchy process. This method firstly rank sub indicators according to their contributions to its higher level indicators, and then define the relative ratio of contributions of sub indicators. Finally, the weights can be calculated. The indices and weighting used to identify geographic poverty in rural China are shown in Table 1 . This indicator system contained as many indicators as possible for rural China in county level and covered almost all the important parts of the DFID framework.

\subsection{Method and technical process for geographic identification of rural poverty}

According to the analyses of the DFID framework above, other things being equal, the state of household livelihood is determined mainly by the quantities and qualities of its livelihood assets, and the vulnerability context influences livelihood status through direct or indirect impact on the "pentagon of livelihoods". Furthermore, it is quite helpful for a household to improve its livelihood status by developing its advantaged dimensions, while having disadvantages in certain dimensions may threaten the sustainability of livelihood. In this study, the composite livelihood status was measured by integrating the five dimensions of livelihood assets at the county level, and then adjusting the resulting score by accounting for the number of advantaged and disadvantaged dimensions. The adjusted result served as the reference for identifying multidimensional poverty. The counties that were identified as poor were grouped by their advantaged and disadvantaged dimensions. Fig. 2 is a flowchart that illustrates the steps that were followed, and the technical details of the study methods are given below.

(1) The chosen indices were first normalized and aggregated hierarchically to obtain a composite score for each dimension, and then the composite scores were normalized again. Min-max normalization was used to limit the score of each dimension to a value between 0 and 1 . After ranking the normalized composite score, four cutoff scores were defined for each dimension. The four cutoff scores were then used to stratify counties into five groups with ascending values, i.e., deprived, disadvantaged, average, advantaged or rich, in that order. The absolute poverty threshold designated by the Chinese government in 2011 was 2300 RMB of net per capita income of rural residents. The relative poverty threshold widely used internationally was $50 \%$ of the median net per capita income of rural residents in 2010. These two thresholds approximately correspond to the 2- and 10-quantiles of counties. Therefore, the bottom $2 \%$ and $2-10 \%$ and the top $2-10 \%$, and $2 \%$ of counties in financial dimension were defined as deprived, disadvantaged, advantaged, and rich, respectively. Although poverty is currently viewed as 
Table 1

Indices and weighting used for geographic identification of poverty in rural China.

\begin{tabular}{|c|c|c|c|c|c|}
\hline Dimension & Index & Feature indicator & Weigl & Attribute indicator & Weight \\
\hline \multirow{3}{*}{$\begin{array}{r}\text { Financial } \\
\text { capital }\end{array}$} & Net income of money or other goods & Net income & 1 & Net per capita income of rural residents & 1 \\
\hline & Savings & - & - & - & - \\
\hline & Loans or borrowings & - & - & - & - \\
\hline \multirow[t]{7}{*}{$\begin{array}{l}\text { Human } \\
\text { capital }\end{array}$} & \multirow[t]{2}{*}{$\begin{array}{l}\text { Rate of labor; composition of their age, sex; nutrition and } \\
\text { health condition }\end{array}$} & \multirow[t]{2}{*}{$\begin{array}{l}\text { Composite capability of } \\
\text { labor }\end{array}$} & \multirow[t]{2}{*}{1} & $\begin{array}{l}\text { Percentage of rural people aged 15-19 (male/ } \\
\text { female) }\end{array}$ & $\begin{array}{l}0.33 \\
(0.59 / \\
0.41)\end{array}$ \\
\hline & & & & $\begin{array}{l}\text { Percentage of rural people aged 20-59 (male/ } \\
\text { female) }\end{array}$ & $\begin{array}{l}0.67 \\
(0.59 / \\
0.41)\end{array}$ \\
\hline & \multirow[t]{3}{*}{ Level of education } & \multirow{3}{*}{$\begin{array}{l}\text { Composite level of } \\
\text { education }\end{array}$} & \multirow[t]{3}{*}{0.6} & Rate of illiteracy of rural residents & 0.125 \\
\hline & & & & $\begin{array}{l}\text { Percentage of rural people with education no } \\
\text { higher than senior-high-school }\end{array}$ & 0.25 \\
\hline & & & & $\begin{array}{l}\text { Percentage of rural people with education no } \\
\text { lower than college }\end{array}$ & 0.625 \\
\hline & \multirow[t]{2}{*}{ Type and extent of trainings/skills/job experience } & \multirow{2}{*}{$\begin{array}{l}\text { Composite competent of } \\
\text { jobs }\end{array}$} & \multirow[t]{2}{*}{0.4} & Percentage of rural agricultural population & 0.41 \\
\hline & & & & Percentage of rural non-agricultural population & 0.59 \\
\hline \multirow{4}{*}{$\begin{array}{l}\text { Natural } \\
\text { capital }\end{array}$} & \multirow{2}{*}{$\begin{array}{l}\text { Area and quality of different agricultural lands (farmland, } \\
\text { grassland, garden land, ponds) }\end{array}$} & \multirow{2}{*}{$\begin{array}{l}\text { Composite level of } \\
\text { farmland }\end{array}$} & \multirow[t]{2}{*}{0.7} & Average area of farmland per rural person & 0.3 \\
\hline & & & & Average grain production per sown area & 0.7 \\
\hline & The amounts and quality of available water resources & Level of water resources & 0.3 & Average precipitation for ten years & 1 \\
\hline & $\begin{array}{l}\text { The amounts and quality of other resources (scene, } \\
\text { animals or plants, energy or minerals) }\end{array}$ & - & - & - & - \\
\hline \multirow[t]{4}{*}{$\begin{array}{l}\text { Physical } \\
\text { capital }\end{array}$} & $\begin{array}{l}\text { The availability and quality of infrastructures and public } \\
\text { services }\end{array}$ & $\begin{array}{l}\text { Level of public } \\
\text { infrastructures and } \\
\text { services }\end{array}$ & 0.18 & Percentage of transportation land & 1 \\
\hline & Numbers and quality of housing & Level of housing & 0.14 & Average number of rooms per rural person & 1 \\
\hline & $\begin{array}{l}\text { The types and numbers of livestock and tools for } \\
\text { production }\end{array}$ & Level of mechanization & 0.28 & $\begin{array}{l}\text { Average power of agricultural machinery per } \\
\text { rural person }\end{array}$ & 1 \\
\hline & $\begin{array}{l}\text { The amounts and quality of appliances, instruments and } \\
\text { other durable goods }\end{array}$ & Level of electricity usage & 0.4 & Average electricity consumption per rural person & 1 \\
\hline \multirow[t]{3}{*}{ Social capital } & $\begin{array}{l}\text { The distribution, income and occupation of close } \\
\text { relationships }\end{array}$ & Level of urbanization & 0.5 & Rate of urbanization & 1 \\
\hline & $\begin{array}{l}\text { Situation of participating in social groups or political } \\
\text { events }\end{array}$ & Level of social support & 0.5 & Income ratio between rural and urban residents & 0.7 \\
\hline & Chances of supports from social institutes or processes & & & 100 - percentage of minorities in rural area & 0.3 \\
\hline \multirow[t]{2}{*}{$\begin{array}{l}\text { Vulnerability } \\
\text { context }\end{array}$} & \multirow[t]{2}{*}{$\begin{array}{l}\text { The extent of exposure to sudden natural or human } \\
\text { disasters or evil trends }\end{array}$} & \multirow[t]{2}{*}{$\begin{array}{l}\text { Level of vulnerability of } \\
\text { context }\end{array}$} & \multirow[t]{2}{*}{1} & $\begin{array}{l}\text { Percentage of areas with gradients higher than } \\
15^{\circ}\end{array}$ & 0.6 \\
\hline & & & & $\begin{array}{l}100 \text { - percentage of people older than } 80 \text { in rural } \\
\text { area }\end{array}$ & 0.4 \\
\hline
\end{tabular}

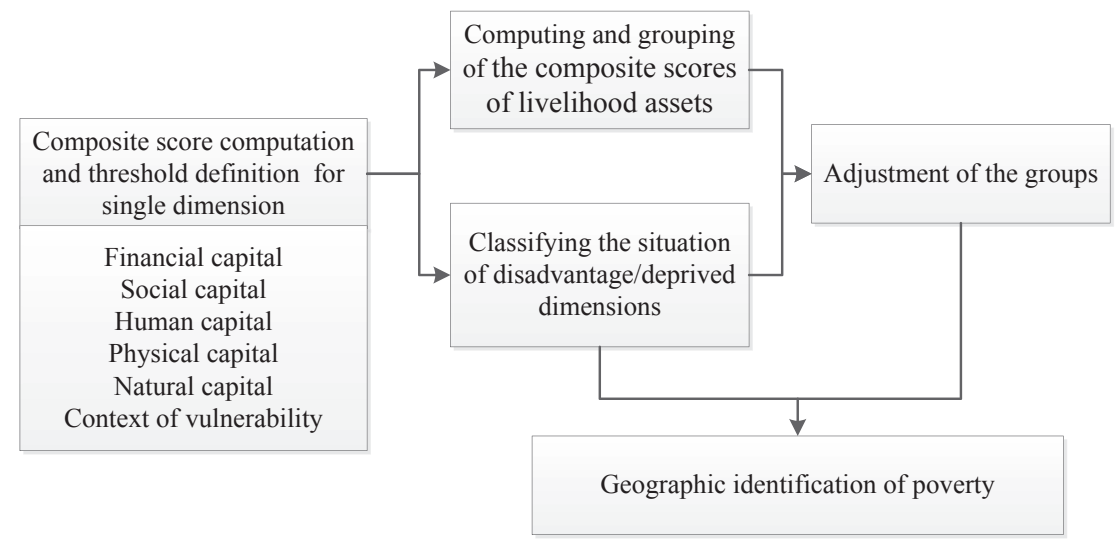

Fig. 2. Flowchart of the steps in geographic identification of multidimensional poverty in rural China.

multidimensional, income or economic poverty is accepted as the core criterion or basic dimension of poverty. Consequently, the definition of cutoff scores that delineate the other five dimensions referred to the financial dimension.

(2) The composite scores of the five dimensions of livelihood assets were combined into a single Multidimensional Development Index (MDI). Many other investigators have simply used the weighted sum or counting method to describe multidimensional poverty. However, in this study we expressed the relationships, or interactions, of the five dimensions graphically by computing the area of the pentagon of livelihoods from their composite scores, as shown below in Fig. 3.

If the composite scores for the five dimensions of livelihood assets of rural households in county $i$ are $a, b, c, d$, and $e$, then the "pentagon of livelihoods" of county $i$ is the inner pentagon $F_{i} H_{i} S_{i-}$ $N_{i} P_{i}$. For a regular pentagon, the angle between two nearby dimensions would be $\alpha\left(\alpha=360^{\circ} / 5\right)$ and the area $S$ of the "pentagon of livelihoods" would be: 


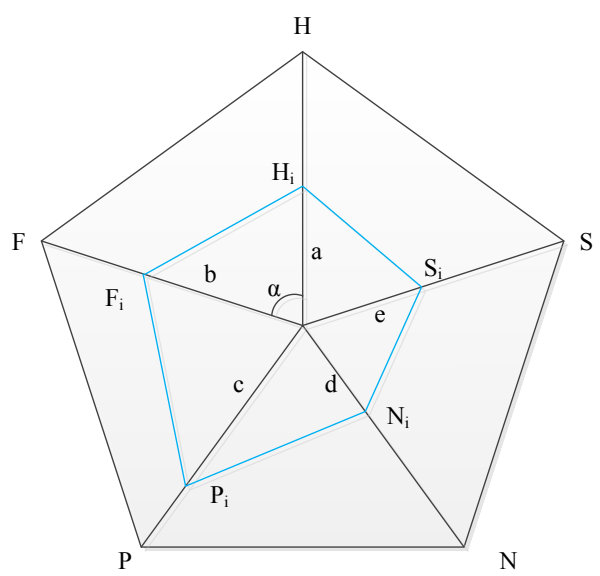

Fig. 3. Structure of the "pentagon of livelihoods" of county $i$.

$S=(a b+b c+c d+d e+e a) * \sin \alpha / 2$

In fact, there is no clear sequence for these five dimensions, but differences in the sequence of the five dimensions will affect the results, so adopting the average area of all the possible pentagons of county $i$ is more reliable. It can be inferred that the poverty rank of this average area depends on the sum of the products of the five composite scores, and that value is defined as the MDI:

$\mathrm{MDI}=a b+b c+c d+d e+e a+a c+c e+e b+b d+d a$

This equation not only effectively expresses the partially mutual substitutable relationship of the five livelihood asset dimensions, but it also accurately explains the effects of the composition of the five assets on sustainable household livelihood. If differences in the composite scores of the five dimensions in a county are small, then the MDI value will be relatively large, indicating good sustainability and low risk of decrease in livelihood status of the county.

(3) Counties were classified into five preliminary classes by their MDI value and then the classification was revised by the rich/ advantaged and disadvantaged/deprived characteristics of all six dimensions. The basis of the revision is that the final classification value for each county was equal to the value of the preliminary classification plus the value of adjustment $\left(A_{d}\right)$. The equation for calculating $A_{d}$ was:

$A_{d}=N_{r} * 1+N_{a} * 0.5-N_{d a} * 0.5-N_{d} * 1$

where, $\mathrm{N}_{\mathrm{r}}, \mathrm{N}_{\mathrm{a}}, \mathrm{N}_{\mathrm{da}}$, and $\mathrm{N}_{\mathrm{d}}$ are the number of rich, advantaged, disadvantaged, and deprived dimensions.

(4) Counties with a final classification value $\leq 1.5$ were classified as multidimensionally poor with reference to the number of counties recently designated as poor by the Chinese central government. The counties classified as poor in this study were grouped according to the properties of their combined advantaged and disadvantaged dimensions.

\subsection{Data and resources}

The study area includes 2354 counties of 31 provinces all over China except Hong Kong, Macau and Taiwan. For the convenience of readers to get acquaintance to the location of these provinces and spatial distribution of rural poverty in China, Fig. 4 is a map of provinces in China and Fig. 5 illustrates the 14 concentrated poverty-stricken areas designated by Chinese government in 2012 .

The study used geographical (e.g., digital elevation model, precipitation, land use, county boundaries) and social and economic (e.g., rural population, labor, education level, average revenue, rate of urbanization, and agricultural conditions) data. The DEM was obtained from the Geospatial Data Cloud Website ${ }^{1}$ and comprised $90 \times 90$ m elevation units abstracted from an SRTM3 image that included the whole region of China. Precipitation data was downloaded from the Data Sharing Infrastructure of the Earth System Science $^{2}$ and included the average annual precipitation with spatial revolution of $1000 \times 1000 \mathrm{~m}$. The land use data was extracted from a 1:100,000 map which was read from a thematic mapper (TM) image obtained in 2000 by the Institute of Remote Sensing Applications, Chinese Academy of Sciences. The county boundaries were those in a 2004 map from the National Geomatics Center of China. Data on population, labor and education level, and urbanization of counties was from the 2010 population census. Data on average revenue and agricultural condition were from the China Statistical Yearbook for Regional Economy 2011 and provincial level and rural statistical reports issued in 2011. Among them, population census of China is a one-time investigation and registration of all natural persons across China from house to house and person to person at the required time. It was conducted by applying the same method, investigation questionnaires and reference time. The data at individual or household level is not released publicly. The data this paper used is the aggregated data at the county level. The sources of the other social and economic data from other statistical yearbooks are sampling surveys at the end of 2010 . The county level is the minimum administrative unit of data that covers all regions of China and is released publicly.

\section{Results}

\subsection{Composite score of single dimensions}

Fig. $6 \mathrm{a}-\mathrm{f}$ shows the spatial distribution of the normalized composite scores of six dimensions. The highest financial capital dimension values were located in the coastal region of eastern China, urban regions in central China, and the border region of northern China. Low values were found in mountainous regions of Yanshan-Taihang, Qinba, the Loess Plateau, the southwestern region of the Tibetan Plateau, and the Yungui Plateau. The human capital dimension scores from areas of northern end, Yangtze River delta, Pearl River delta and the plain of Hubei and Hunan were the highest. Scores for the Tibetan Plateau and Yungui Plateau were the lowest. The spatial distribution of scores for the natural capital dimension revealed a Higher-High-Low-High trend spreading from the southeast to the northwest, with the lowest value located within a belt stretching from the eastern part of Inner Mongolia to the Loess Plateau and then to the Tibetan Plateau. Regional differences in the social capital dimension were similar to the financial capital dimension, except that the values were more varied. The entire coastal region of eastern China and parts of western and northern Inner Mongolia were rich in the physical capital dimension, but regions of Loess Plateau, Tibetan Plateau, Yungui Plateau, and the western Xinjiang province are deprived in that dimension. The effect of the context of vulnerability on the status of livelihood is opposite that of the other dimensions. Generally speaking, vulnerability context was high in plateau and mountainous regions and low in flat regions such as plain and river valleys.

\footnotetext{
${ }^{1}$ http://www.gscloud.cn/listdata/showinfo_new.shtml?from=\&id=306.

2 http://www.geodata.cn/Portal/metadata/viewMetadata.jsp?id=100101-30.
} 


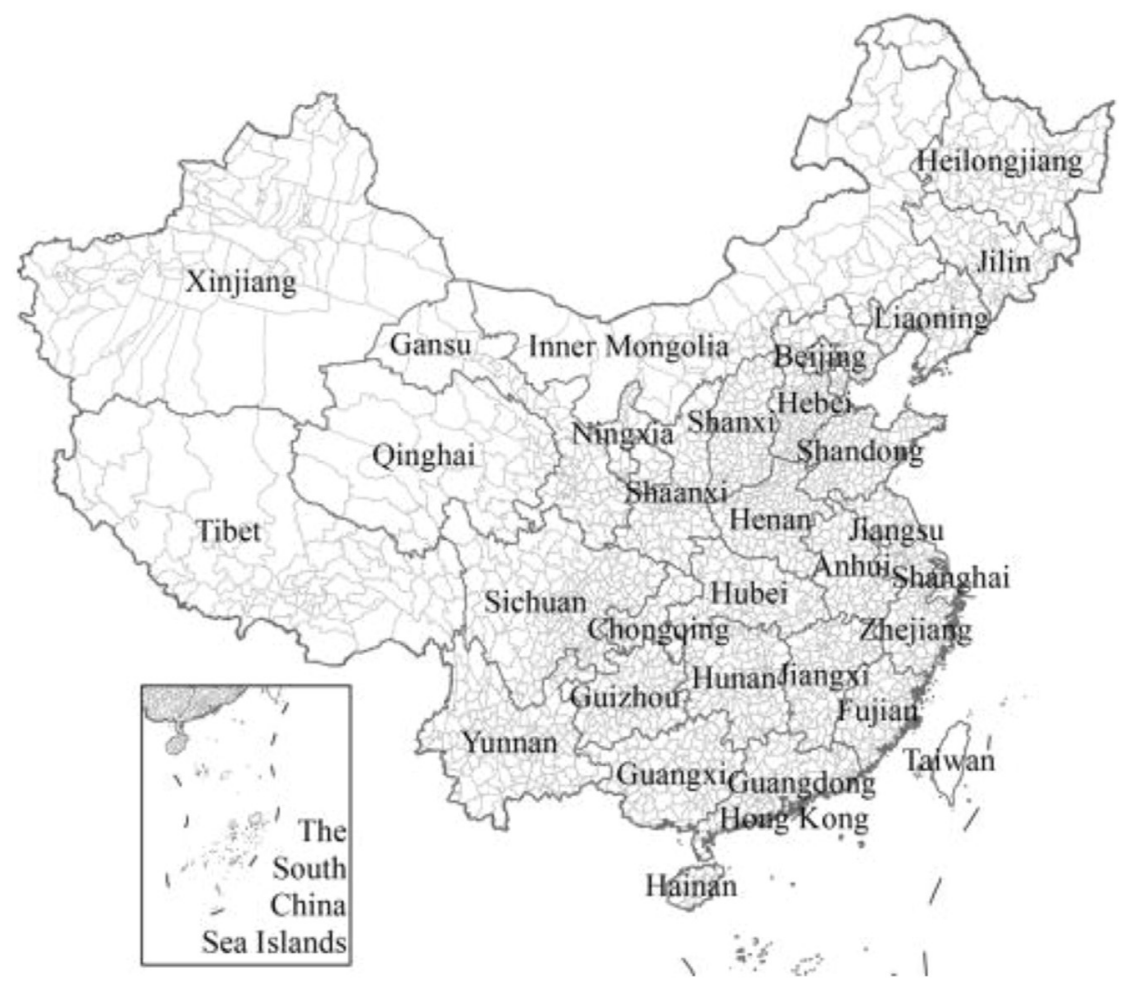

Fig. 4. Provinces of China.

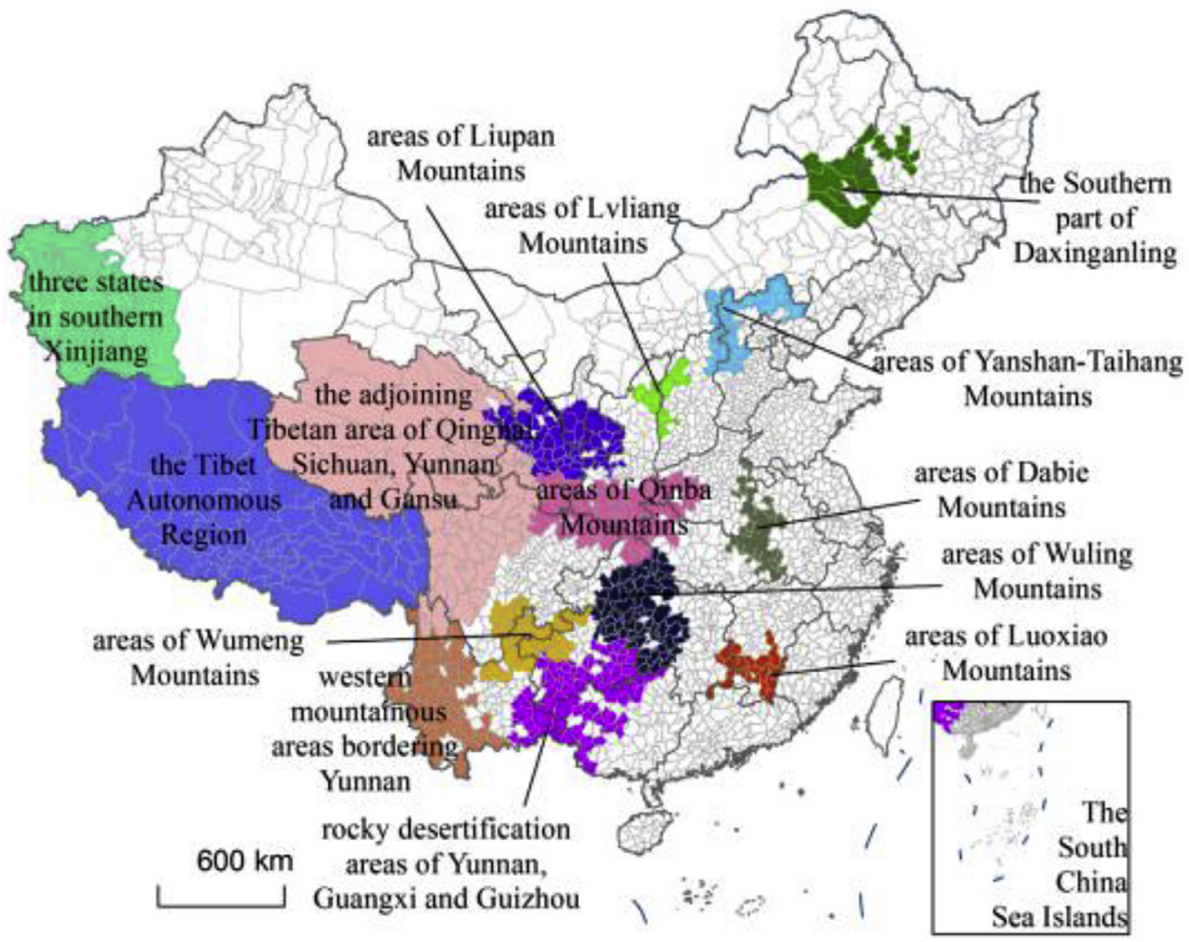

Fig. 5. The 14 concentrated poverty-stricken areas in China.

Concentrations of high vulnerability regions in the Loess Plateau, the southeastern Tibetan Plateau, plateaus and mountainous areas in western Sichuan and Yunnan provinces, southern Gansu province, rocky desert regions of Yunnan, Guizhou and Guangxi, mountainous areas of Qinba, and the border contiguous with $\mathrm{Hu}-$ nan, Hubei and Guizhou are clearly visible in Fig. 6f. There was also a continuous distribution of high vulnerability regions in mountainous regions of western Xinjiang province, Wuyi, YanshanTaihang, and Qilian.

From the analysis of single dimensions above, it is clear that large areas of intersection existed for the advantage and disadvantage values in all six dimensions. The overlapping areas of 

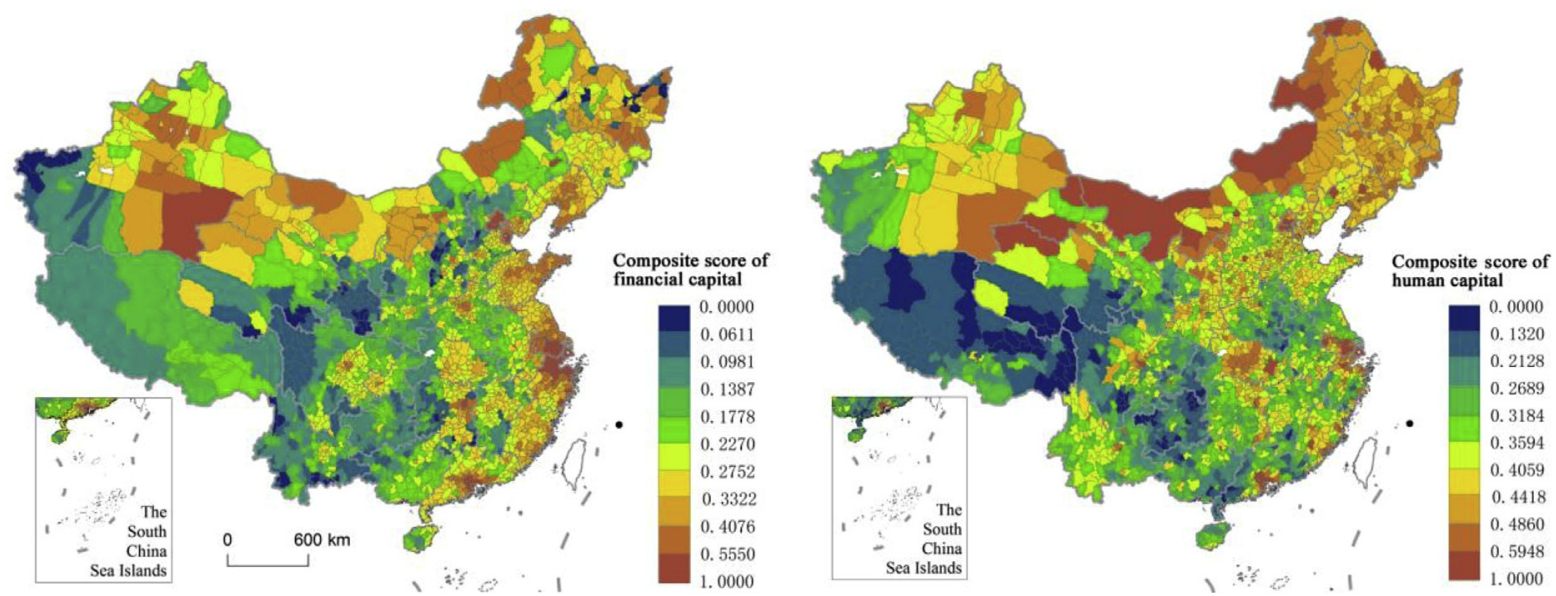

(a) Financial capital

(b) Human capital
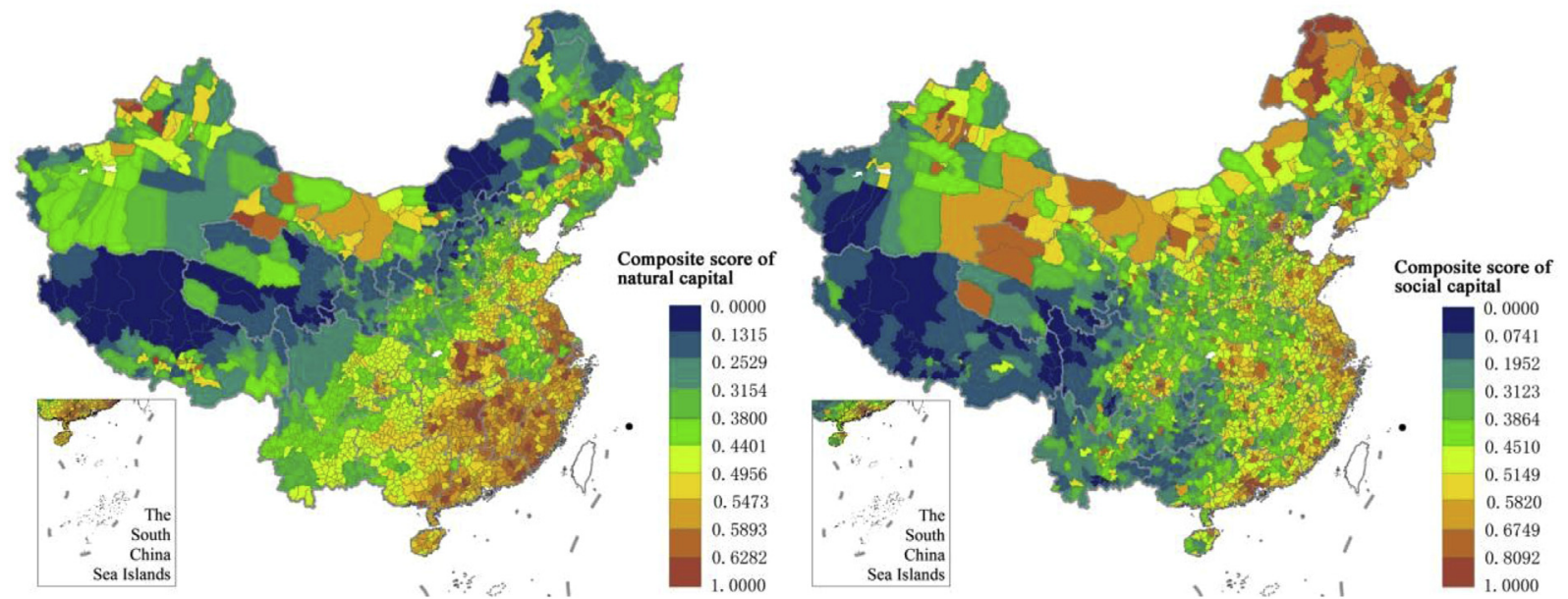

(c) Natural capital

(d) Social capital
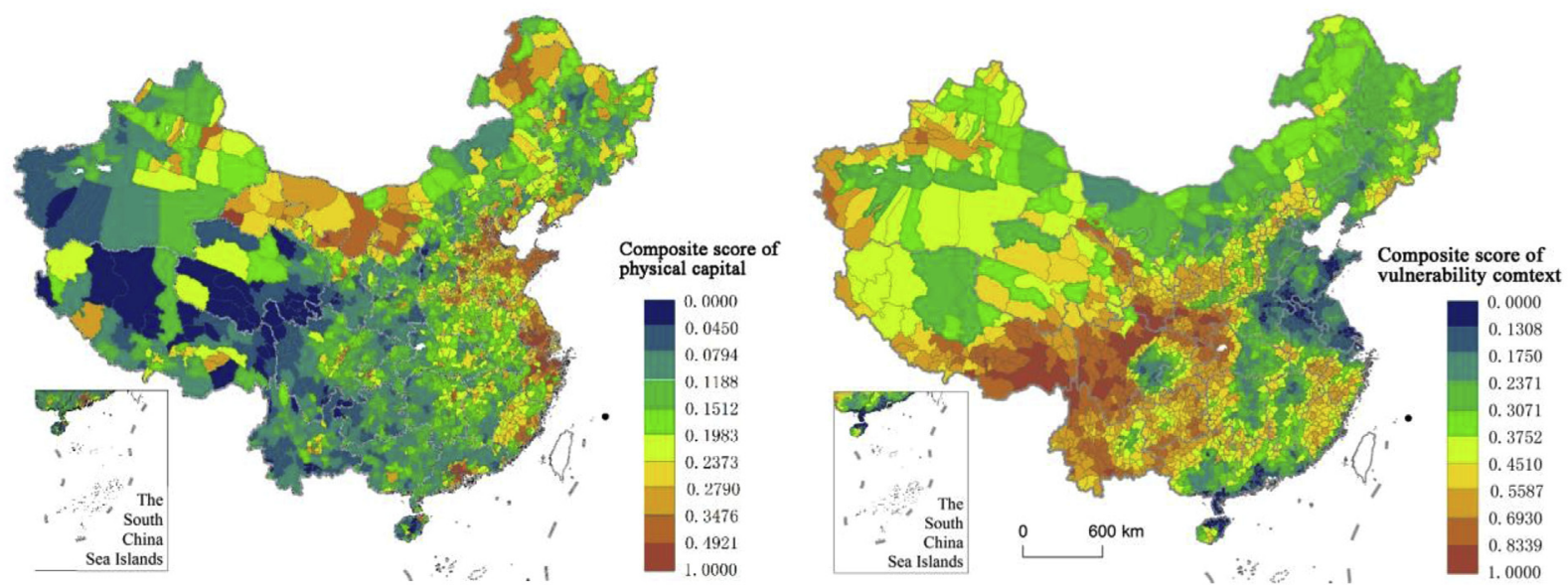

(e) Physical capital

(f) Context of vulnerability

Fig. 6. Spatial distribution of the normalized composite scores of each dimension. 
disadvantage values mainly concentrated at central and western areas of plateaus and mountains, including Qingzang Plateau, Yungui Plateau, hilly areas of Loess Plateau, three states in southern Xinjiang, area of Qinba mountains, Yanshan-Taihang mountains and Wuling mountains. At the same time, the overlapping areas of advantage values clustered at the three growth regions of China, i.e., Beijing-Tianjin, the Yangtze delta and the Pearl River delta, economic centers of each province and their neighboring areas and areas of plains, including Huanghuaihai Plain, Northeast Plain, Chengdu Plain and the Yangtze River Plain. The spatial distribution showed that both the physical geographic conditions and economic status have significant impacts on all six dimensions.

Beyond these areas of intersection, the six dimensions also showed different spatial distributions depending on their particular emphases. To be specified, the dimension of financial capital is closely related with conditions of agricultural and non-agricultural industries, transportation and location, and policies for development of farmers, agriculture and rural areas. The dimension of human capital is more related to conditions of transportation and location, education, non-agricultural economy, traditional thoughts of local people, population and related policies. The dimension of physical capital has closer relationship with conditions of landform, economic development and policies on infrastructure investment. The dimension of natural capital more depends on landform and soil-water-photo-thermal conditions, biodiversity and available water resources. The dimension of social capital is more concerned with ethnic composition, transportation and location, urbanization, connection between urban and rural areas. The dimension of vulnerability context is highly related with landform, weather, ecological environment and natural disasters.

These areas of spatial intersection and differentiation revealed the partially mutual substitutable relationship of the six dimensions, indicated the importance of measurement of multidimensional poverty, and proved, to some extent, the reasonability of the method proposed by this research. Besides, by measuring all the six dimensions and defining divisions of each dimension, it is very easy to find the advantage/rich dimensions and disadvantage/ deprived dimensions of each geographic unit. Therefore, it will facilitate policymakers to develop specific, targeted preliminary antipoverty policies or programs according to the disadvantaged/ deprived dimensions and their combinations in multidimensionally poor counties to improve the "shortest board" of poor peoples' sustainable livelihood, and take additional measures according to the rich/advantage dimensions to develop local economy and expand livelihood strategies for local people in pursuit of an effective and sustainable breakthrough to eliminate poverty.

\subsection{MDI and poverty identification}

The MDI is determined by combining all five livelihood asset dimensions as described above. The spatial distribution of MDI values in Fig. 7 shows that counties with the lowest MDI were located in plateau and mountainous areas of southwestern China, in areas near the Yinshan, Yanshan, Taihang, Lvliang, and Wuling mountain ranges in central China, and mountainous areas of southern Qinghai, southern and eastern Gansu, southern Ningxia, and three states in southern Xinjiang of northwestern China. Counties included in the lower value group were located mainly in regions surrounding counties with lowest values. The majority were in Xinjiang and Shannxi in the northwest, Heilongjiang, and Inner Mongolia in the northeast, and within all provinces in central China. Counties in the highest and higher value groups were concentrated in coastal areas of eastern China and widely distributed in the plains and river valleys of northeastern, central, and western China.

These five MDI groups were adjusted by the rich/advantaged and disadvantaged/deprived characteristics of all six dimensions. The spatial distribution of counties following value adjustment is shown in Fig. 8. As it shows, disadvantaged and deprived counties are concentrated in southwestern China, and clusters of rich and advantaged counties are seen in northern and eastern China. A contiguous area extending south of Qinghai, north of Tibet, and northwest of Sichuan is the most deprived region in all six dimensions, and has the lowest adjustment values except for a few counties in the mountainous provinces of Xinjiang, Gansu, Yunnan, Guizhou, Guangxi, and Shanxi where the $A_{d}$ was also less than -2.5.

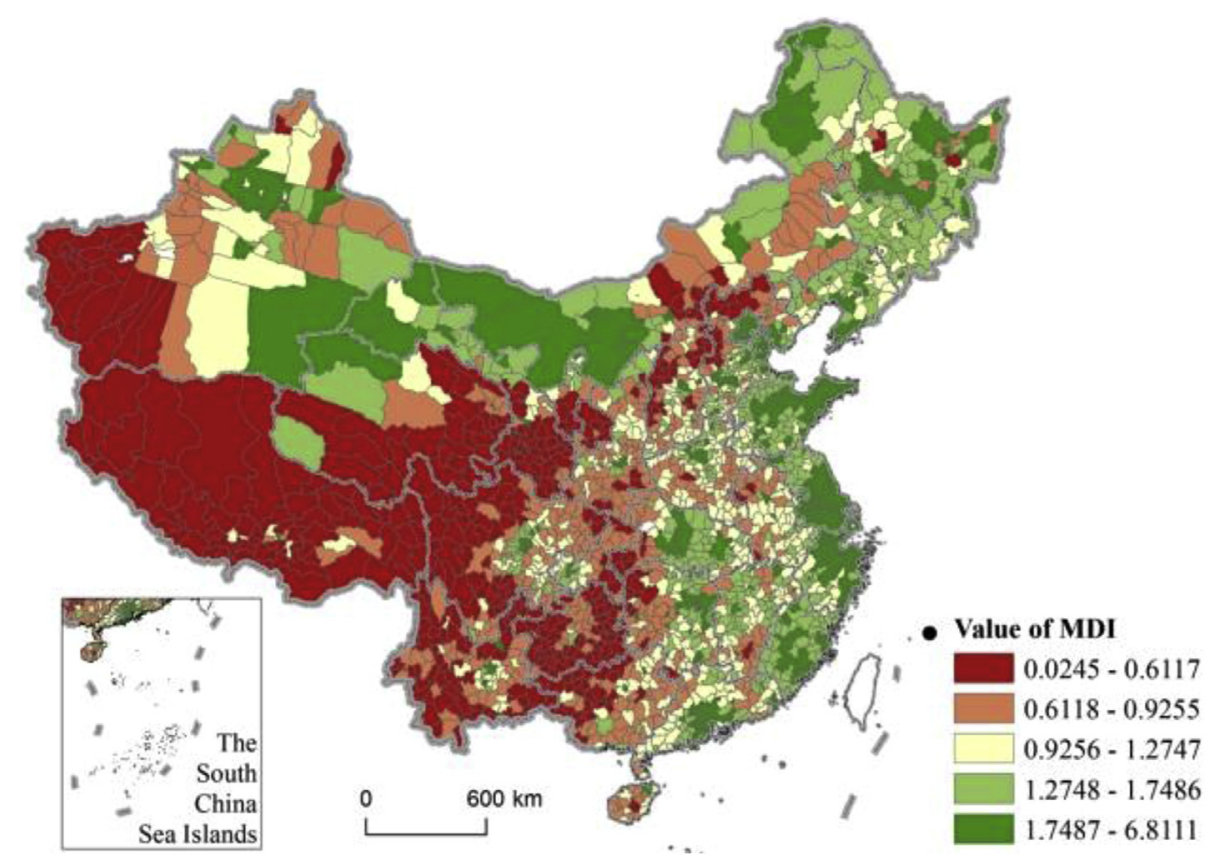

Fig. 7. Spatial distribution of MDI. 


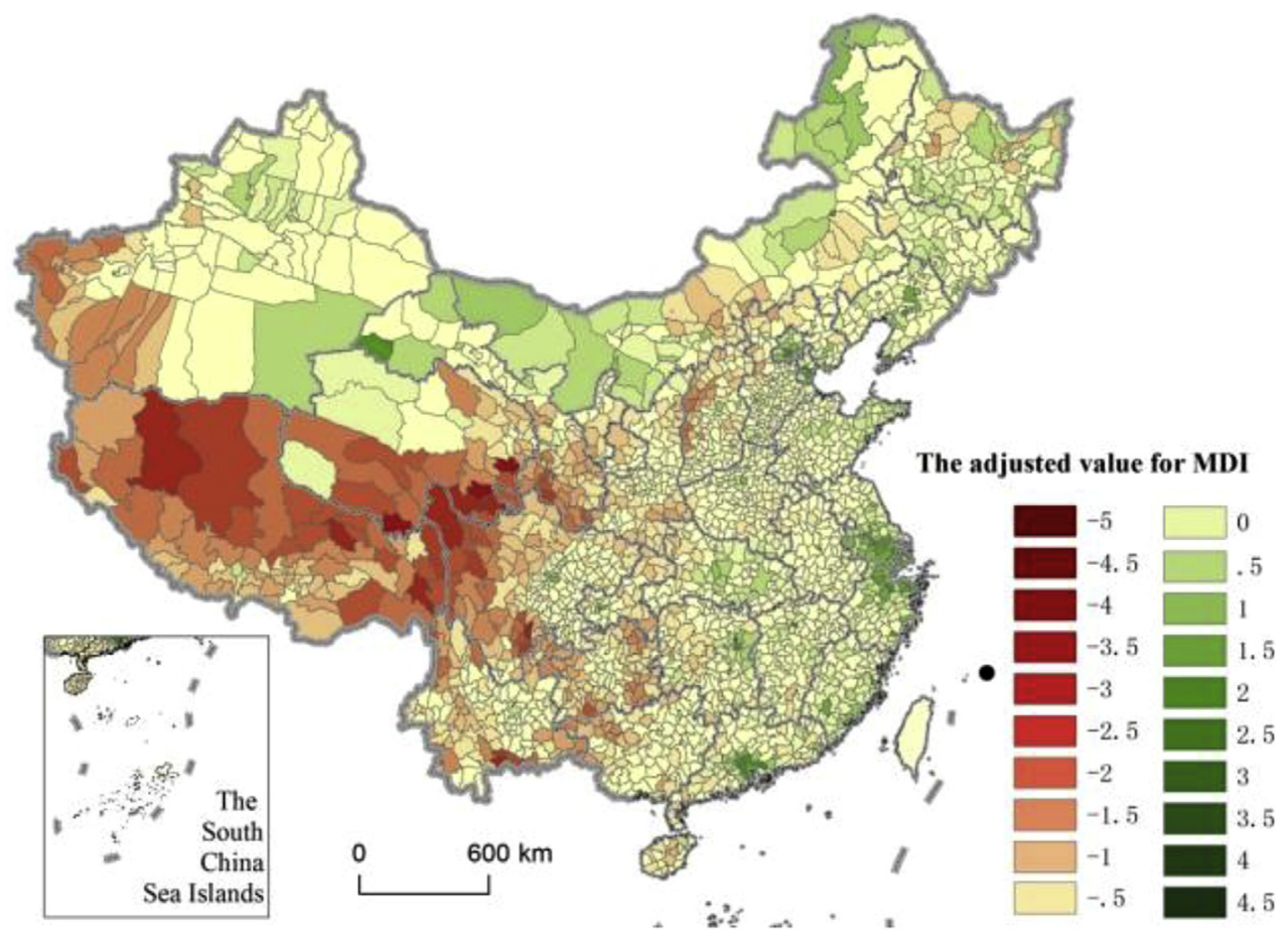

Fig. 8. Spatial distribution of MDI adjustment value.

The majority of rich/advantaged counties with an $A_{d}>2.5$ are in the central areas of three growth regions of China, i.e., Beijing-Tianjin, the Yangtze delta and the Pearl River delta. A few counties in provinces of Liaoning, Hebei, Inner Mongolia, Fujian, and Hunan also had an $A_{d}>2.5$. Counties with $A_{d}$ values between -2.5 and 0 mainly cluster in the transition zone from the second to the third step of China's landscape and include mountainous and valley regions in south of Xinjiang, northeast of Qinghai, south of Gansu, west of Sichuan, and northwest of Yunnan. Counties with $A_{d}$ values between 0 and 2.5 are mainly located in the flat, coastal regions of eastern China, the plains of central and northeastern China, the Zhungeer basin area of north Xinjiang, and the relatively flat area of Inner Mongolia from Alashan to Hetao and from northeast of Xilinguole to Hulunbeier.

After the adjustment of MDI, the multidimensional development levels of counties in rural China were determined (Fig. 9). The group with the lowest adjusted values was identified as multidimensionally poor. Compared with the preliminary MDI groups, change mainly occurred in counties with an $A_{d}$ between -1.5 and 1.5. A total of 655 counties with 141 million rural residents in 23

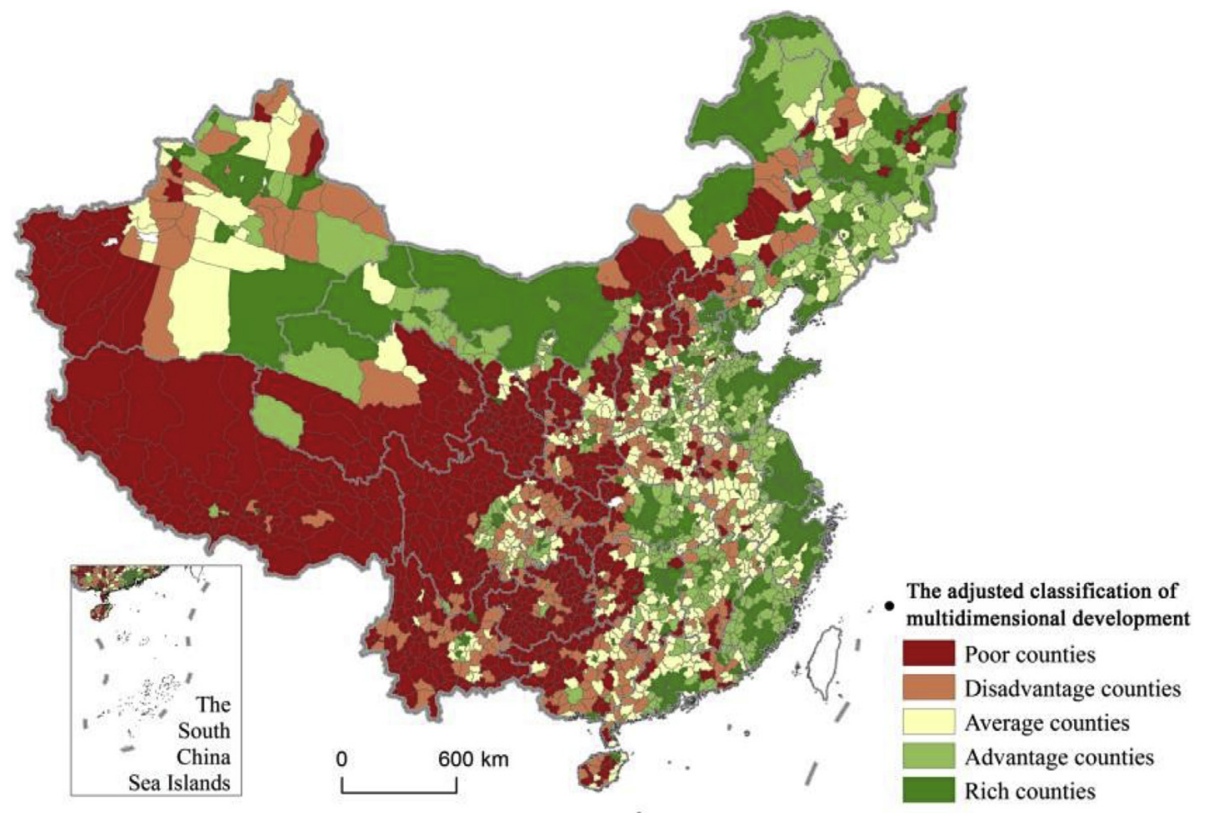

Fig. 9. Classification of multidimensional development level after MDI adjustment. 
provinces were identified as multidimensionally poor. They are densely distributed geographically in the Tibetan Plateau and the neighboring three states in southern Xinjiang, the Yungui Plateau, the Loess Plateau, and areas of the Wuling, Qinba, and Daxinganling-Yanshan-Taihang mountains. Other poor counties are located in mountainous regions of Dabie Mountain, south of Jiangxi, Guangxi, and Hainan. These regions are mainly in the provinces of western China (including Guangxi) where they comprise either the highest number or greatest proportion of poor counties. In central China, Shanxi, followed by Hunan, and Inner Mongolia, has many more, and a higher proportion of, poor counties than other provinces. In the coastal region of eastern China, Guangdong and Hainan have seven poor counties each.

As shown in the spatial distribution of these multidimensional poor counties, areas of plateaus, mountains and hills are the concentration region for multidimensional poverty. Majority of these areas are spatially remoted, isolated and ecologically vulnerable. Evil conditions for agricultural development and underdeveloped non-agricultural industry make it hard for local residents to boost income. Inadequate public infrastructure and services lead to a deficiency of physical and human capitals. In addition, with high proportion of minority people inhabited and large gap of living standards between urban and rural residents, social exclusion in these areas is severe.

\subsection{Comparisons and appraisal}

\subsubsection{Multidimensional poverty and income poverty}

The multidimensionally poor counties identified in this study were compared with single-dimension, income-poor counties. Thresholds of $\$ 1.25$ per day per person and $60 \%$ of the median income were used as standards to define absolute and relative poverty, respectively. After currency conversion, these thresholds were about $3000 \mathrm{RMB}$ and $4000 \mathrm{RMB}$ per year and counties with a net per capita income of rural residents below those thresholds were identified as absolutely and relatively poor counties. There were 215 counties below the absolute poverty threshold and 594 below the relative poverty threshold, with populations of 46.38 million and 131 million rural residents, respectively.

Most of the income-poor counties that concentrated in poverty- stricken areas previously designated by the Chinese government in 2012 were also identified as multidimensionally poor shown in Fig. 10. The regions include three states in southern Xinjiang, the western border area of Tibet, the adjoining Tibetan area of Qinghai, Sichuan, Gansu and Yunnan, the western mountainous area bordering Yunnan, rocky desertification areas of Yunnan, Guangxi, and Guizhou, areas of the Wumeng mountains of Sichuan, Yunnan and Guangxi, the Liupan mountains west of Qinghai, east of Gansu, and south of Ningxia, the Qinba mountains of Gansu, Shaanxi, Sichuan, Hubei, Chongqing, and Henan, the Wuling mountains of Hunan, Hubei, and Guizhou, the Lvliang mountains of Shanxi, and the Yanshan-Taihang mountains of Inner Mongolia, Hebei, and Shanxi. Almost all the MDI values of those counties placed them in the lowest group. Most of the counties that located in mountainous areas of central or eastern China and mountainous areas of Qinba of Sichuan, and Chongqing have only one disadvantaged or deprived dimension. Most of the counties in mountainous areas of western China and the Lvliang Mountains of Shanxi have multiple disadvantaged or deprived dimensions.

Seven absolute income-poor counties do not have multidimensional poverty. All are located in central China, three in Hunan, two in Heilongjiang, one in Jiangxi and one in Hebei. A total of 109 relatively income-poor counties do not have multidimensional poverty. Most of them are in central China, including Hebei, Jiangxi, Hubei, and Hunan; a few of are in provinces of western China, including Sichuan, Yunan, Shaanxi, and Gansu. Among 116 incomepoor counties, 88 had an MDI value placing them the lower group, 26 were in the middle group, and the remaining two counties, A'ershan in Inner Mongolia and Shiyan City in Hubei province, were in the advantaged group. None of the 116 counties had disadvantaged or deprived dimensions and some had advantaged dimensions. For instance, Shiyan City and A'ershan had advantaged human and social capital dimensions. Huitong, Wugang, and Shuangfeng in Hunan province, Quannan in Jiangxi province, and Rikaze in Tibet province had advantaged natural capital dimensions. Longjing in Jilin province had an advantaged human capital dimension; and Zanhuang in Hebei province and Gaolan in Gansu province had advantaged physical capital dimensions.

A total of 177 counties with multidimensional poverty are not in the list of income-poor counties. The majority are located in central

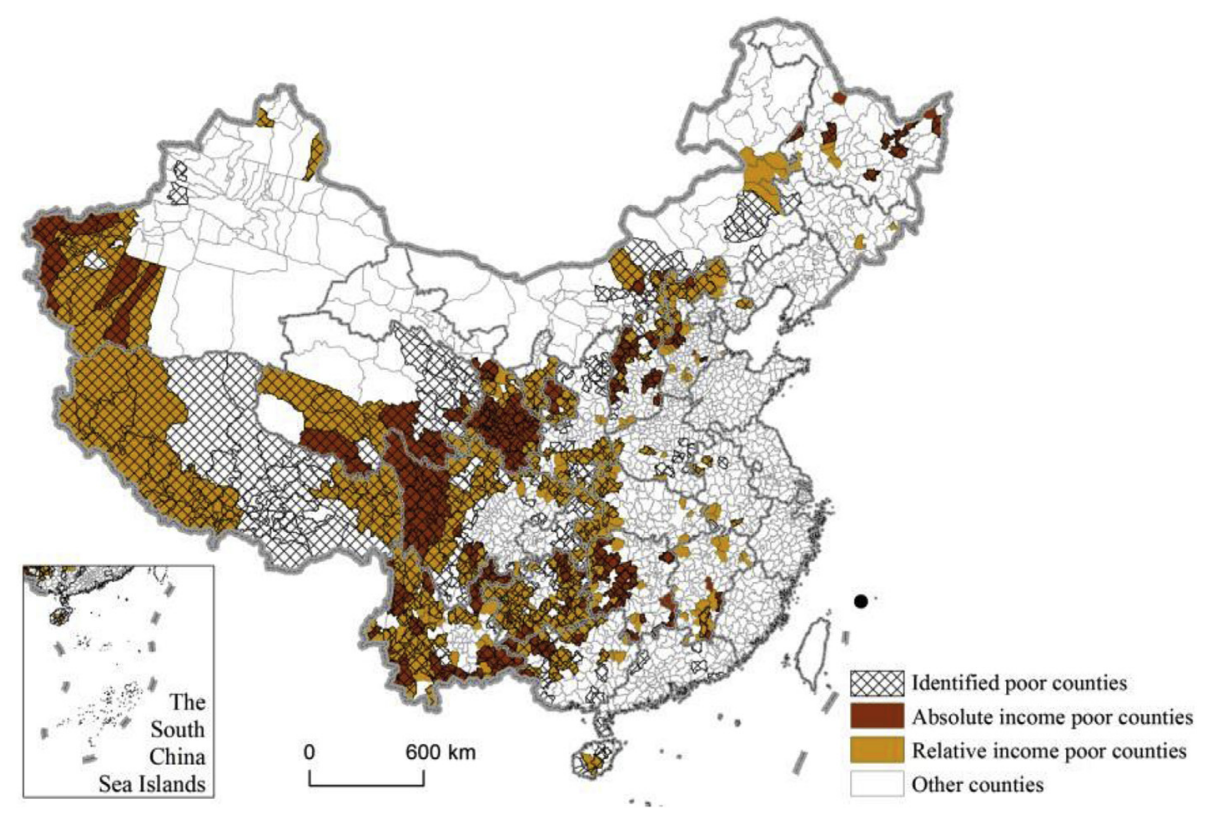

Fig. 10. Counties with multidimensional poverty or income poverty. 
Table 2

Poverty statistics ${ }^{\mathrm{a}}$ of designated poor and identified poor counties.

\begin{tabular}{|c|c|c|c|c|c|c|}
\hline \multirow[t]{2}{*}{ Dimension } & \multicolumn{3}{|c|}{ Designated poor counties (592) } & \multicolumn{3}{|c|}{ Identified poor counties (655) } \\
\hline & Min & Max & Mean & Min & Max & Mean \\
\hline Financial capital & 1096 & 9628 & 3475 & 1096 & 6849 & 3513 \\
\hline Human capital & 0.0101 & 0.5480 & 0.2929 & 0.0101 & 0.5480 & 0.2662 \\
\hline Social capital & 0.0521 & 0.6779 & 0.2865 & 0.0325 & 0.5561 & 0.2522 \\
\hline Physical capital & 0.0202 & 0.2680 & 0.1016 & 0.0159 & 0.2564 & 0.0905 \\
\hline Natural capital & 0.0301 & 0.6306 & 0.3628 & 0.0168 & 0.6636 & 0.3366 \\
\hline Context of vulnerability & 0.1108 & 0.8901 & 0.4619 & 0.0680 & 0.8901 & 0.5084 \\
\hline MDI & 0.0313 & 2.1094 & 0.5943 & 0.0245 & 0.9206 & 0.4868 \\
\hline
\end{tabular}

a To better exhibit the actual distribution of these dimensions, the values for each dimension and MDI are original composite scores before normalization, but the value for

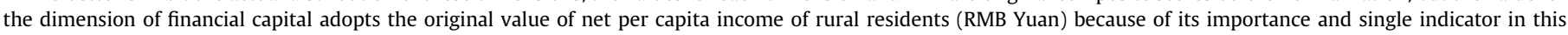
dimension.

Tibet, eastern and northeastern Qinghai, the marginal mountainous and Tibetan areas of Sichuan and Chongqing, the coast of the Yellow River, and the Qinba mountains in northern Shaanxi. Most multidimensionally poor counties of Guangdong, Inner Mongolia, Henan, Hainan, and southeastern Guangxi are also in this group. The net per capita income of rural residents in all these counties is between 4002 and $6849 \mathrm{RMB}$, which is slightly above the income-poverty threshold and below the average income. The MDI value of these counties placed them in the lowest or lower group; most have at least one disadvantaged or deprived dimension. The counties in central Tibet, eastern, and northeastern Qinghai generally have more than two disadvantaged or deprived dimensions, and most of the remaining counties have only one disadvantaged or deprived dimension. Specifically, the mountainous counties along the Yellow River in Shanxi, Inner Mongolia, and Shaanxi have disadvantaged or deprived natural capital dimensions. Counties in Anhui, Henan, Chongqing, Guizhou, Guangdong, and eastern Sichuan have disadvantaged or deprived human capital dimensions. Counties in Hainan have disadvantaged physical capital dimensions. Counties in mountainous areas of Qinba in Shaanxi and mountainous and Tibetan areas of western Sichuan have a disadvantaged or deprived vulnerability context.

\subsubsection{Identified and designated poor counties}

The 655 counties identified as multidimensionally poor have 141 million rural residents; the 592 counties designated as poor by the Chinese central government in 2012 have 158 million rural residents. Table 2 lists the major statistics of the six single dimensions and the composite MDI for the two categories of poor counties. The poverty statistics revealed that the poor counties identified in the study were more accurately targeted as the counties with the worse rural sustainable livelihood. Almost all the extreme and mean values of the five dimensions of livelihood assets and MDI were much lower in the identified than the designated poor counties, the intervals of their extreme values were much smaller, and the dimension of vulnerability context was larger.

A total of 425 counties were both identified poor and designated poor (Fig. 11), accounting for $71.8 \%$ of the designated poor counties. These counties are mainly in the mountainous provinces of Xinjiang, Yunnan, Guizhou, Guangxi, Chongqing, Hunan, Gansu, Ningxia, Shanxi, and Heilongjiang. ${ }^{3}$ In addition, 527 of the identified poor counties are included in 14 concentrated poverty-stricken

\footnotetext{
${ }^{3}$ To be clear, in consideration of their own economic capacity on poverty reduction, the Chinese government had not designated any poor counties in coastal provinces of eastern China since 2000. But that does not mean there are no poor counties in these provinces. In this research, 7 counties of Guangdong province are identified as multidimensional poor counties.
}

areas designated by Chinese government, accounting for $78 \%$ of the listed counties. Furthermore, the identified poor counties account for more than $70 \%$ of those listed in 11 concentrated povertystricken areas, including the Tibet Autonomous Region, three states in southern Xinjiang, the adjoining Tibetan area of Qinghai, Sichuan, Gansu and Yunnan, western mountainous areas bordering Yunnan, rocky desertification areas of Yunnan, Guangxi and Guizhou, and mountainous areas of Wumeng, Liupan, Qinba, Wuling, Lvliang, and Yanshan-Taihang. Only a few of the identified poor counties appear in the lists of the other three concentrated povertystricken areas, including the mountainous areas of Dabie, Luoxiao, and the Southern part of Daxinganling.

Of the remaining 167 designated poor counties that did not appear in the list of identified multidimensionally poor counties, 108 counties were classified as disadvantaged. The majority are in provinces of central China, and a few are in provinces of western China. Forty-seven counties classified as average are mainly in provinces of central or northeastern China. Most of the 108 disadvantaged and 47 average counties do not have disadvantaged or deprived dimensions, but their MDI and net per capita income of rural residents are not high. Nine of the 167 counties are advantaged and three are rich, all 12 are in central and northwestern China and have an above average MDI. None of them have disadvantaged or deprived dimensions; several have some advantaged dimensions. There were 162 counties identified as multidimensionally poor (except for counties of Tibet ${ }^{4}$ ) that are not designated poor counties. Most are in western provinces; a few are in Shanxi, Hunan and Guangdong. All have a MDI that placed them in the lowest or lower group, and the majority have at least one disadvantaged or deprived dimension.

\section{Conclusions and discussions}

\subsection{Conclusions}

The accurate identification of poverty is an important issue in China today because of its impact on programs designed to reduce rural poverty, avoiding loss of anti-poverty funds, and improving the effectiveness of anti-poverty programs. One of the main reasons for the low accuracy of poverty identification in China is a continuing focus on the economic dimension even though poor

\footnotetext{
${ }^{4}$ Though 68 counties in Tibet, with 2.1 million rural residents, are identified as multidimensional poor counties that are not designated poor counties, it is noteworthy that Chinese government has designated the Tibet Autonomous Region, including its whole 73 counties, as one concentrated poverty-stricken area that has exclusive preferential poverty-reduction policies since 2000. Moreover, it would not change the statistical result obtained from Table 2 if data of Tibet was removed from the statistics of identified poor counties.
} 


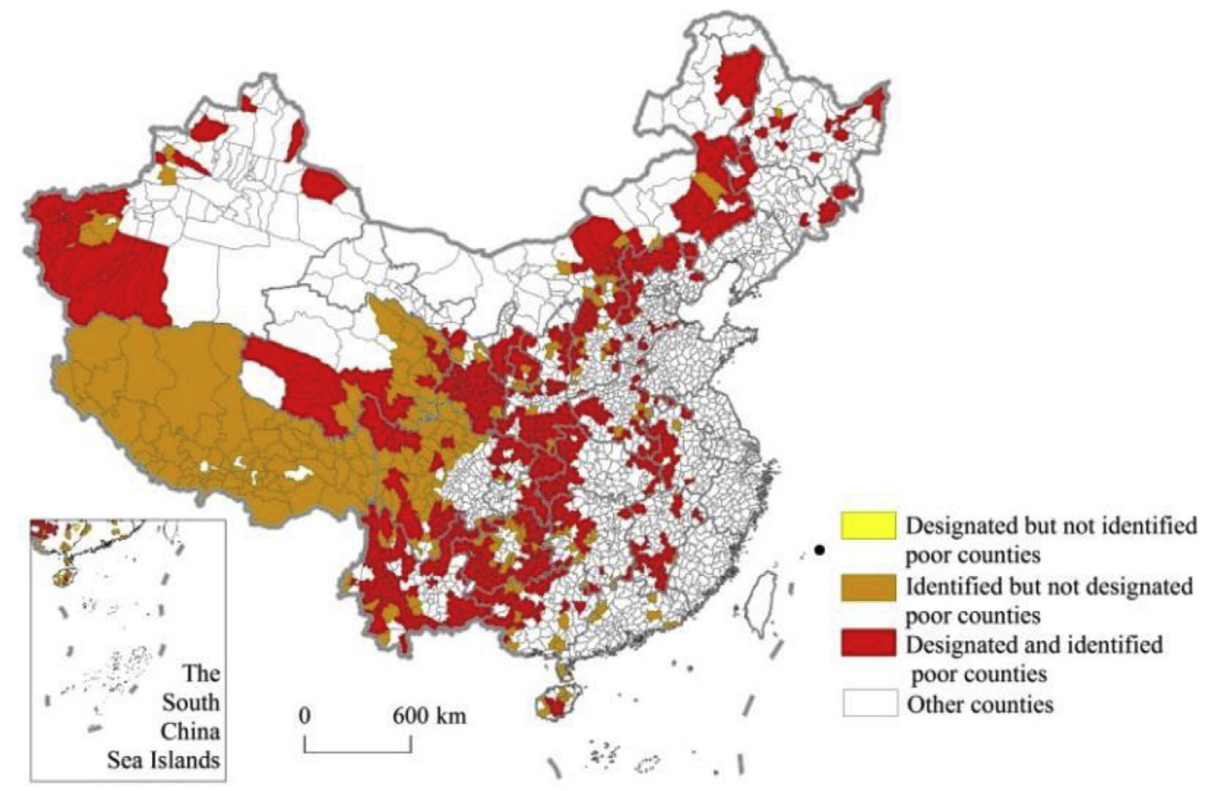

Fig. 11. Spatial distribution of identified poor and designated poor counties.

rural populations experience more complex deprivation. This paper is one of the pioneering studies in China that aims to develop a method of its own to measure multidimensional poverty in rural area, and, as far as we know, it is a very rare paper that carries out a county-level measurement of multidimensional poverty covering almost the whole territory of China and makes comparison of the identification result with poor counties designated by Chinese government. We hope this paper could really contribute to the literature on rural poverty and the practice of poverty reduction in China. At the same time, as measurement of multidimensional poverty has recently become a hot topic in poverty research worldwide, the development and use of a new method of identifying multidimensional poverty in rural China adds to the knowledge of this topic. The main conclusions are listed below.

(1) As a relatively systemic and comprehensive framework for poverty analysis, the DFID framework is very useful for capturing the disadvantage/deprived characteristics of poor people dynamically and multidimensionally. Taking the DFID framework as the research basis, by establishing an index system and developing a composite Multidimensional Development Index (MDI), this study proposed and used an integrated method for geographical identification of multidimensional poverty in rural China. The method can better reflect the impact of multiple factors on the livelihood of rural populations and offers increased accuracy of poverty targeting in rural China.

(2) A total of 655 counties in 23 provinces and including 141 million rural residents, were identified as multidimensionally poor counties. They are concentrated and conjointly distributed geographically. The largest poor region includes the Tibetan Plateau and neighboring areas of southern Xinjiang, the western Loess Plateau, and mountain and valley areas of western Yunnan and Sichuan. Concentrations of poor counties were also identified in the Wumeng-Daliang mountains and rocky desertification areas of Yunnan, Guizhou and Guangxi provinces, bordering mountainous areas of Yunnan province, areas of the Wuling, Qinba, and YanshanTaihang mountains and valleys of Shanxi and Shaanxi provinces. This spatial distribution suggested that physical geographic and environmental basis is still one of the main reasons for the remaining poor people experiencing multidimensional deprivations.

(3) Compared with income poor counties and designated poor counties, the identified multidimensionally poor counties not only accurately targeted at most counties in economic poverty, but also identified those counties with multidimensional disadvantages or deprivations. Of the designated poor counties, $71.8 \%$ were also identified as multidimensional poor counties. Most are located in the central areas of mountainous regions in western China. By contrast, the majority of the designated poor counties that are located in mountainous regions in central or eastern China were not identified as multidimensionally poor counties because they do not have many disadvantaged/deprived dimensions of the livelihood of rural populations. However, the multidimensional poor counties that are mainly distributed at the margins of plateau or mountainous regions of western China, with multiple dimensions with disadvantages and deprivations, are not included among the designated poor counties. By improving the accuracy of targeting, this method of identification of multidimensional poverty could help Chinese government to promote the effectiveness of poverty reduction, and it could also be used as a reference for other countries or regions that seeks to target at poor people with multidimensional deprivations.

(4) At the same time, the measurement of multidimensional poverty could help policymakers to develop specific, targeted preliminary antipoverty policies or programs according to the disadvantaged/deprived dimensions in multidimensionally poor counties to improve the "shortest board" of poor peoples' sustainable livelihood, and take additional measures according to the rich/advantage dimensions to develop local economy and expand livelihood strategies for local people in pursuit of an effective and sustainable breakthrough to eliminate poverty. As for China, the sustainable livelihoods of the remaining poor rural people have long been constrained by large geographic scale 
of natural context of resources and environment. Therefore, regional antipoverty programs have to be designed to cope with these natural constraints first, and it should be believed that only by this way can the other more pointed antipoverty programs directly oriented at poor individuals/households be more effective and sustainable for poverty reduction.

\subsection{Discussions}

Poverty issue itself is a complicated giant system that involves too many aspects. It evolves with the development of economy and society, but never disappears. It is hard enough to learn all the contents it included, not to mention quantifying it accurately. Just like it is said in the guidance sheets of DFID framework, the framework is only a simplification; it 'does not attempt to provide an exact representation of reality. It does, however, endeavor to provide a way of thinking about the livelihoods of poor people that will stimulate debate and reflection, thereby improving performance in poverty reduction'. So is this paper. Relying on the possibility that the DFID framework provides for examining poverty multidimensionally and dynamically, connecting the difficulties that China faces in its practice of poverty reduction, this research tries to quantify the DFID framework and measure multidimensional poverty in rural China, and also hopes to provide a reference for other countries. As an exploratory study, there are still many places that are open to question, especially for the choices that were made from the DFID framework to operationalized measures.

(1) The content that each part of the DFID framework includes is not totally agreed yet. The definition of them in this paper is only one way of understanding connecting with China's own situation. Surely, these contents and their according indicators could and should be different for different studies, different countries and regions. Besides, questions like whether the effect of each asset working on the outcome of livelihood is the same and can one type of capital be substituted for others are still in dispute. By analyzing the determinants of each dimension, this research proved the partially mutual substitutable relationship of the five assets but could not sequence them because massive empirical studies were needed to realize it.

(2) In the choices of indicators, the emphasis of the DFID framework is put on the scale of household, while the data and the analysis are provided at the scale of counties. It should be noted that this may cause ecological problem though the authors have done their best to avoid. Meanwhile, the accuracy of the indicators selected is also open to question, because the quality of data at regional level is hard to control and some indicators were substituted or abandoned for the data availability reason. Moreover, the weights allocated for integration of indicators of each dimension were mainly from subjective judgement according to experience and other people's research. It would be more convincing if they were obtained from massive empirical studies.

(3) In the part of the method inference (Section 2.1), to simplify the analysis and avoid the influence of existing structures and processes on the estimation of the conditions of livelihoods, the spatial disparity of existing structures and processes is neglected and households are supposed to be economically rational. Actually, the existing structures and processes and the livelihood strategies that households used to adopting are quite different in different places, and they may impose important impacts on the livelihood outcomes of households. Therefore, there are many aspects in these two fields that are worthy to be studied. For example, research upon the behaviors of households in different region and possessing different status of livelihood responding to the existing policies, institutions and processes and what the actual livelihood outcomes and households' appraisals are; the preferences of households in different region or possessing different status of livelihood for livelihood strategies and which the most effective ones are. These kinds of studies can definitely improve the measurement of sustainable livelihoods of households and make great contribution to the effects assessment of antipoverty policies. Furthermore, they could help to optimize the operational strategies and the actual effectiveness of antipoverty policies and programs.

In addition, further research could be made to test the usefulness and accuracy of this newly proposed method by comparing the result of measurement with results obtained by using data from other years or applying methods developed outside of China. On the one hand, the measurement of multidimensional poverty in rural China was based on data in just one year because of data availability. Therefore, the result of identification may vary for other different years, especially for those counties with composite score nearing the threshold value, and it could not help readers to better understand the geography of poverty reduction in China. Actually, the spatial distribution of designated rural poor counties in China has been relatively stable since 1986 . It surely will reveal more interesting features if we could make more measurements using data from other different years and then make a comparison between different years. On the other hand, since most methods for measuring multidimensional poverty developed outside of China, such as the Multidimensional Poverty Index (MPI), need micro data from household surveys, further comparisons cannot be implemented. At the same time, indices developed worldwide to measure human well-being beyond economic advancement that do use regional scale data, such as Human Development Index (HDI), also cannot be estimated because lack of partial data at county level in rural China. The main differences between HDI and MDI lie in selection and integration of indicators. HDI takes four indicators in three dimensions of health, education and living standards, and aggregates them with equal weights into a composite statistic (UNDP, 2010b). Though health was not included in MDI and education was measured differently, we believe the results should be comparable if the demanded data of life expectancy at birth, mean years of schooling and expected years of schooling are available at county level in rural China. Furthermore, we are confident that MDI would reveal more features than HDI, and might be more reasonable for the different integration method of dimensions.

\section{Acknowledgements}

This study was funded by National Natural Science Foundation of China (Project No. 41171449), Knowledge Innovation Project of the Chinese Academy of Sciences (Project No. KZZD-EW-06).

\section{References}

Achia, T. N. O., Wangombe, A., \& Khadioli, N. (2010). A logistic regression model to identify key determinants of poverty using demographic and health survey data. European Journal of Social Sciences, 13(1), 38-45.

Alkire, S., \& Foster, J. (2011). Counting and multidimensional poverty measurement. Journal of Public Economics, 95(7), 476-487.

Alkire, S., \& Santos, M. E. (2010). Acute multidimensional poverty: A new index for developing countries. OPHI Working Paper 38.

Atkinson, A. B. (2003). Multidimensional deprivation: Contrasting social welfare and counting approaches. Journal of Economic Inequality, 1, 51-65. 
Bourguignon, F., \& Chakravarty, S. (2003). The measurement of multidimensional poverty. Journal of Economic Inequality, 1(1), 25-49.

Cannon, T., Twigg, J., \& Rowell, J. (2003). Social vulnerability: Sustainable livelihoods and disasters. Report to DFID Conflict and Humanitarian Assistance Department (CHAD) and Sustainable Livelihoods Support Office http://www.benfieldhrc. org/disaster_studies/projects/soc_vuln_sust_live.pdf.

Cao, S., Wang, X., \& Wang, G. (2009). Lessons learned from China's fall into the poverty trap. Journal of Policy Modeling, 31(2), 298-307.

Cavatassi, R., Davis, B., \& Lipper, L. (2004). Estimating poverty over time and space: Construction of a time-variant poverty index for Costa Rica. ESA Working Paper No. 04-21.

Chambers, R., \& Conway, G. (1992). Sustainable rural livelihoods: Practical concepts for the 21st century. IDS Discussion Paper 296. Brighton, England: Institute of Development Studies.

Chen, L. (2008). Measurement of multiple-dimensional poverty and its decomposition during the period of transition in China. Economic Review, 5, 5-11 (in Chinese).

Chen, M., Guo, Y., \& Yu, Z. (2011). An improved method for rank correlation analysis and its application. Journal of Systems and Management, 20(3), 352-355 (in Chinese).

Cohen, A. (2009). The multidimensional poverty assessment tool: Design, development and application of a new framework for measuring rural poverty. Rome: International Fund for Agricultural Development.

Davis, B. (2003). Choosing a method for poverty mapping. Rome: Food and Agriculture Organization of United Nations.

Deichmann, U. (1999). Geographic aspects of inequality and poverty. Text for World Bank's web site on inequality, poverty and socio-economic performance. http:// www.worldbank.org/povertyu/inequal/index.htm.

DFID. (1999-2005). Sustainable livelihoods guidance sheets. London: Department for International Development (UK). http://www.eldis.org/go/ home\&id=41731\&type $=$ Document\#.U9DchbeKDIU.

Dorling, D., Rigby, J., Wheeler, B., Ballas, D., Thomas, B., Fahmy, E., et al. (2007). Poverty, wealth and place in Britain, 1968 to 2005. Bristol: Policy Press.

Ellis, F. (2000). Rural livelihoods and diversity in developing countries. Oxford: Oxford University Press.

Ferreira, F., \& Lugo, M. A. (2012). Multidimensional poverty analysis: Looking for a middle ground. ECINEQ working paper 251.

Frankenberger, T. R., Drinkwater, M., \& Maxwell, D. (2000). Operationalizing household livelihood security: A holistic approach for addressing poverty and vulnerability. http://www.fao.org/docrep/003/X9371e/x9371e12.htm.

Glauben, T., Herzfeld, T., Rozelle, S., \& Wang, X. (2012). Persistent poverty in rural china: Where, why, and how to escape? World Development, 40(4), 784-795.

Henninger, N. (1998). Mapping and geographic analysis of poverty human welfare: Review and assessment. Report prepared for the UNEP/CGIAR Initiative on GIS. Washington, D.C., USA: World Resources Institute.

Hulme, D., Moore, K., \& Shepherd, A. (2001). Chronic poverty: Meanings and analytical frameworks. CPRC Working Paper 2.

IFAD. Background documents for SLA. http://www.ifad.org/sla/background/index. htm.

Krishna, A. (2007). For reducing poverty faster: Target reasons before people. World Development, 35(11), 1947-1960.

Krishna, A., Lumonya, D., Markiewicz, M., Mugumya, F., Kafuko, A., \& Wegoye, J. (2006). Escaping poverty and becoming poor in 36 villages of Central and Western Uganda. Journal of Development Studies, 42(2), 346-370.

Labar, K., \& Bresson, F. (2011). A multidimensional analysis of poverty in china from 1991 to 2006. China Economic Review, 22(4), 646-668.

Li, X., Dong, Q., Rao, X., \& Zhao, L. (2007). Vulnerability analysis approach and its localization application. Chinese Rural Economy, 4, 32-39 (in Chinese).

Li, G., Qiu, D., Wang, L., Wang, P., \& Luo, D. (2012). Impacts of difference among livelihood assets on the choice of economic compensation pattern for farmer households farmland protection in Chongqing city. Acta Geographica Sinica, 67(4), 504-515 (in Chinese).

Liu, X., Su, S., Wang, Y., Huang, Y., \& Zhao, Y. (2014). The index system of spatial poverty of village level to monitor in concentrated contiguous areas with particular difficulties. Scientia Geographica Sinica, 34(4), 447-453 (in Chinese).

Maasoumi, E., \& Lugo, M. A. (2008). The information basis of multivariate poverty assessments. In Kakwani, \& Silber (Eds.), Quantitative approaches to multidimensional poverty measurement. Palgrave Macmillan.

Neto, A. (2001). Poverty alleviation policies: The problem of targeting when income is not directly observed. Serie Economia Discussion Paper.

Nhate, V., \& Simler, K. (2003). Poverty, inequality, and geographic targeting: Evidence from small-area estimates in Mozambique. Washington, DC: International Food Policy Research Institute.

Park, A., \& Wang, S. (2010). Community development and poverty alleviation: An evaluation of China's poor village investment program. Journal of Public Economics, 94(9), 790-799.

Park, A., Wang, S., \& Wu, G. (2002). Regional poverty targeting in China. Journal of Public Economics, 86(1), 123-153.

Ravallion, M. (2009). Are there lessons for Africa from China's success against poverty? World Development, 37(2), 303-313.

Ravallion, M. (2011). On multidimensional indices of poverty. Journal of Economic Inequality, 9(2), 235-248.

Riskin, C. (1994). Chinese rural poverty: Marginalized or dispersed? American Economic Review, Papers and Proceedings, 84(2), 281-284.

Roberts, M. G., \& Yang, G. (2003). The international progress of sustainable development research: A comparison of vulnerability analysis and the sustainable livelihoods approach. Progress in Geography, 22(1), 11-21 (in Chinese).

Sen, A. (1982). Poverty and famines: An essay on entitlements and deprivation. Oxford: Clarendon Press.

Sen, A. (1985). A sociological approach to the measurement of poverty: A reply to Professor Peter Townsend. Oxford Economic Papers, 37(4), 669-676.

Sharp, K. (2003). Measuring destitution: Integrating qualitative and quantitative approaches in the analysis of survey data. IDS Working Paper 217.

Tsui, K. Y. (2002). Multidimensional poverty indices. Social Choice and Welfare, 19(1), 69-93.

United Nations Development Programme. (2010a). The Millennium Development Goals Report 2010. http://www.undp.org/content/dam/fiji/docs/Vanuatu_MDG_ 2010.pdf.

United Nations Development Programme. (2010b). Human Development Report 2010. http://hdr.undp.org/en/content/human-development-report-2010.

Wagle, U. (2002). Rethinking poverty: Definition and measurement. International Social Science Journal, 54(171), 155-165.

Wang, X., \& Alkire, S. (2009). Measurement of multiple-dimensional poverty in China: Evaluation and policy implication. Chinese Rural Economy, 12, 4-10 (in Chinese).

Wang, W., Cheng, H., \& Zhang, L. (2012). Poverty assessment using DMSP/OLS nighttime light satellite imagery at a provincial scale in China. Advances in Space Research, 49, 1253-1264.

Wang, X., Li, S., \& Wang, S. (2009). Eliminating poverty through development in china. Oxon, New York: Routledge, Taylor \& Francis Group.

Wang, S., Park, A., Chaudhuri, S., \& Datt, G. (2007). Rural poverty-reduction and village-level poverty targeting of new period in China. Management World, 1, 56-64 (in Chinese).

Wang, Y., Qian, L., \& Duan, F. (2013). Multidimensional poverty measurement and spatial distribution pattern at the country scale: A case study on key country from national contiguous special poverty-stricken area. Scientia Geographica Sinica, 33(12), 1489-1497 (in Chinese).

Wang, Z., Zhang, P. Y., \& Liu, X. L. (1995). The spatial characteristics of natural disasters in China. Acta Geographica Sinica, 50(3), 248-255 (in Chinese).

World Bank. (2000). World Development Report 2000/2001: Attacking poverty. New York: Oxford University Press.

World Bank. (2009). From poor areas to poor people: China's evolving poverty reduction agenda. An assessment of poverty and inequality in China.

Xiong, Y. (2001). A sociological research on poverty in china. In Technical Assistance Team for TA No.3610 ADB on behalf of Asian Development Bank, \& Leading Group Office of Poverty Alleviation, State Council, People's Republic of China (Eds.), Methodology of county poverty alleviation planning in China: A report on methods, guidelines and processes.

Yue, X., Li, S., \& Wang, P. (2005). The causes of transient poverty and its implication to poverty reduction policy in rural China. Colombo, Sri Lanka. In 4th PEP Research Network General Meeting.

Zou, W., \& Fang, Y. (2011). Research on dynamical and multiple-dimensional poverty of China. Chinese Journal of Population Science, (6), 49-59 (in Chinese). 